\title{
Partial Blind Study
}

National Cancer Institute

\section{Source}

National Cancer Institute. Partial Blind Study. NCI Thesaurus. Code C67020.

A study in which the subject, the investigator, or anyone assessing the outcome is aware

of the assignment in at least one treatment group but unaware of the treatment assignment(s) in one or more other treatment groups. 